\title{
Highly specific phosphopeptide enrichment by Titanium(IV) cross-linked chitosan composite
}

\author{
Ting $\mathrm{Wu}^{\mathrm{a}}$, Jiani Shi ${ }^{\mathrm{a}}$, Chuanjing Zhang ${ }^{\mathrm{a}}$, Lingfan Zhang ${ }^{\mathrm{a}^{*}}$, Yiping $\mathrm{Du}^{\mathrm{a}}$ \\ a. Research Centre of Analysis and Test, East China University of Science and Technology, \\ Shanghai 200237, China.
}

*To whom correspondence should be addressed: E-mail: zlf@ecust.edu.cn; Tel:+86-21-64253225.

\begin{abstract}
Natural chitosan was applied as supporting material for Ti(IV) based immobilized metal ion affinity chromatographic (IMAC) material (Ti-CTS). Compared with other polymer based IMAC, Ti-CTS can save the cockamamie synthesis procedures and be easy to obtain. The morphology, surface area, pore volume and elemental composition of Ti-CTS were revealed by scanning electron microscopy (SEM), Brunauer-Emmett-Teller (BET) method and X-ray photoelectron spectroscopy (XPS). Tryptic digest products from several standard proteins and two real samples (non-fat milk and serum) were enriched using Ti-CTS to demonstrate the efficiency of this method. The results showed that this composite enables high sensitive and selective phosphopeptide enrichment from casein variants, non-fat milk and human serum. Furthermore, multi-phosphorylated peptides with three serine phospholated sites $\left(S^{*} S * S *\right)$ demonstrated high affinity to Ti-CTS. Hence, this method had great potential for future studies of complex phosphoproteomes and especially multi-phosphorylated peptides.
\end{abstract}

Keywords: Phosphopeptide enrichment; IMAC; chitosan; MALDI TOF MS. 


\section{Introduction}

Protein phosphorylation plays an important role in protein function regulation and signaling transmission. The abnormal protein phosphorylation is involved in several diseases including cancers[1,2], Alzheimer's disease[3,4] and diabetes[5]. Thus, the analysis of phosphorylated protein is of great interest for understanding biochemical pathways and guiding the clinical diagnostic. Mass spectrometry (MS) has become the most effective and preferred method to detect the phosphorylated peptides because of its high-throughput, simplicity and ultrahigh sensitivity[6, 7]. However, the low abundance of phosphorylated peptides and ion suppression effect arising from nonphosphorylated species in MS analysis make the identification of phosphopeptides remain a challenge. Hence, highly selective and robust enrichment of phosphorylated peptides before MS analysis is vital for MS-based phosphopeptide analysis.

A number of strategies have been developed for phosphopeptide enrichment prior to study of phosphorylation by MS[8-16]. Immunoprecipitation, chemical-modification strategies, strong cation exchange chromatography, immobilized metal ion affinity chromatography (IMAC) and metal oxide affinity chromatography (MOAC) are optional methods for phosphopeptides enrichment. Among them, IMAC and MOAC are the most simple and convenient techniques, and have been widely studied. Immobilized metal ion affinity chromatography (IMAC) relies on the special affinity of the phosphate group to metal ions such as $\mathrm{Ti}^{4+}, \mathrm{Fe}^{3+}, \mathrm{Ga}^{3+}$ and $\mathrm{Zr}^{4+}$ and is frequently used for phosphopeptide enrichment due to its simple preparation. The chelating ligands for metal immobilization in IMAC are always functionalized polymers, such as poly(Glycidyl Propargyl Ether/Divinyl Benzene)[17], poly(GMA-co-TMPTMA)[18], poly(glycidyl methacrylate-co-ethylene dimethacrylate)[19, 20]. Their synthesis process is always 
complicated and time-consuming.

In this study, chitosan was selected as the chelating ligand to cross-link $\mathrm{Ti}^{4+}$. Chitosan is a derivative from $\mathrm{N}$-deacetylation of chitin and have been widely used as biosorbents for $\mathrm{Pd}(\mathrm{II})$ [21], $\mathrm{Cr}(\mathrm{VI})[22,23]$, As (III) and $\mathrm{As}(\mathrm{V})[24], \mathrm{Cu}(\mathrm{II})$ and $\mathrm{Ni}(\mathrm{II})[25]$ from aqueous medium using chitosan-coated biosorbent. Regarding its low cost, environmental friendly feature, the apparent natural abundance and the chelating properties, chitosan-based IMAC has demonstrated its potential capacity in phosphopeptide enrichment[26]. Here, we present the adsorbent qualities of chitosan-based $\mathrm{Ti}^{4+}$-IMAC(Ti-CTS) for the enrichment of phosphopeptides. Ti-CTS was obtained simply by direct cross-linking chitosan and $\mathrm{Ti}^{4+}$. The efficient and facile enrichment of phosphopeptide using Ti-CTS was evaluated prior to matrix-assisted laser desorption/ionization time-of-flight mass spectrometry(MALDI-TOF MS) identification.

\section{Materials and methods}

\subsection{Materials and chemicals}

Chitosan (reagent grade, high-molecular weight) was purchased from Shanghai Weikang Biological Co. (China) with a degree of deacetylation of $91 \%$ and average molecular weight of $400,000 \mathrm{~g} \mathrm{~mol}^{-1} . \alpha$-Casein (from bovine milk), $\beta$-casein (from bovine milk),2,5-dihydroxybenzoic acid (DHB) were obtained from Sigma-Aldrich (St. Louis, MO). Trifluoroaceticacid (TFA), acetonitrile, ammonium bicarbonate, ammonium hydroxide, acetic acid, phosphoric acid and titanium tetrachloride $\left(\mathrm{TiCl}_{4}\right)$ were all of analytical grade and used without further pretreatment. Trypsin was purchased from Promega (Beijing, China). Milli-Q water by Milli-Q system (Millipore, Bedford, MA) was used through the whole experimental process. 


\subsection{Preparation of Ti-CTS composite}

Ti-CTS composite was prepared by a cross-linking reaction between chitosan and $\mathrm{TiCl}_{4}$. Briefly, 2 g chitosan powders were dissolved into $100 \mathrm{~mL} 2 \%(\mathrm{v} / \mathrm{v})$ acetic acid aqueous solution and held for $12 \mathrm{~h}$. Then, $0.1 \mathrm{M} \mathrm{TiCl}_{4}$ was slowly added in the solution and stirred at $100 \mathrm{rpm}$ for $2 \mathrm{~h}$. Subsequently, sodium hydroxide (2.0 M) solution was added drop by drop with the syringe needle to precipitate Ti-CTS composite. Glutaraldehyde aqueous solution (5\%) was added and stirred vigorously for $2 \mathrm{~h}$. The suspension was transferred to a refrigerator at $4^{\circ} \mathrm{C}$ for $24 \mathrm{~h}$ to undergo complete cross-linking reaction and then washed with distilled water to neutral $\mathrm{pH}$ followed by drying at $30{ }^{\circ} \mathrm{C}$ for 2 days.

\subsection{Characterization and Measurements}

The surface morphology of the composite was studied with scanning electron microscope (SEM,JSM-6360LV, JEOL, Japan). Elemental spectra were obtained using X-ray photoelectron spectroscopy (XPS) which allowed a qualitative and relative quantitative detection of elements present in the chitosan composite. The Brunauer-Emmett-Teller (BET) method was utilized to calculate the specific surface areas.

\subsection{Sample Preparation.}

$\alpha$-Casein, $\beta$-casein (from bovine milk, $1 \mathrm{mg}$ ) and bovine serum albumin (BSA) were dissolved in $1.0 \mathrm{~mL}$ ammonium bicarbonate $(50 \mathrm{mM}, \mathrm{pH}$ 8.2) respectively. BSA was reduced with dithiothreitol (DTT) at $50{ }^{\circ} \mathrm{C}$ in a thermomixer for $30 \mathrm{~min}$. Then the solution was cooled down to 
room temperature by the gradual addition of iodoacetamide solution and incubated in dark for 15 min. Then $\alpha$-Casein, $\beta$-casein and BSA were incubated for $18 \mathrm{~h}$ at $37^{\circ} \mathrm{C}$ with trypsin at an enzyme-to-protein ratio of $1: 50(\mathrm{w} / \mathrm{w})$. All of the proteolytic digests were then stored in a refrigerator at $-20^{\circ} \mathrm{C}$ for further use.

Non-fat milk with protein concentration of $33 \mathrm{~g} / \mathrm{L}$ and human serum were diluted 10 times and 20 times with ammonium bicarbonate $(50 \mathrm{mM}, \mathrm{pH} 8.2)$. The digestion of nonfat milk and serum were carried out with the same procedure. After reduction and alkylation, the solution was diluted using $50 \mathrm{mM} \mathrm{NH}_{4} \mathrm{HCO}_{3}$ to make up the volume up to 35 and 70 times (for non-fat milk and serum) of initial sample volume. Then trypsin was added and digestion was carried out at room temperature overnight.

2.5 Enrichment of Phosphopeptides from Tryptic Digestion of Standard Proteins.

Ti-CTS $(200 \mu \mathrm{g})$ was activated with $100 \mu \mathrm{L} 60 \% \mathrm{ACN}$ in $1 \%(\mathrm{v} / \mathrm{v}) \mathrm{TFA}$. Then $100 \mu \mathrm{L}$ of a peptide mixture was added and vibrated at $25{ }^{\circ} \mathrm{C}$ for $30 \mathrm{~min}$. Subsequently, the material was washed with $100 \mu \mathrm{L} 50 \% \mathrm{ACN}$ in $0.1 \%$ (v/v) TFA three times. Then phosphopeptides were eluted with $\mathrm{NH}_{4} \mathrm{OH}$ $(5 \mu \mathrm{L}, 5 \%)$ for $5 \mathrm{~min}$ and analyzed by MALDI-TOF MS. The centrifugation was used after every washing and elution step.

2.6 MALDI-TOF MS Analysis.

The eluent $0.5 \mu \mathrm{L}$ was deposited on the plate, and then $0.5 \mu \mathrm{L}$ of DHB solution $\left(25 \mathrm{mg} / \mathrm{mL}^{-1}\right.$ in $70 \%$ (vol/vol) acetonitrile) containing $\left.1 \%(\mathrm{wt} / \mathrm{vol}) \quad \mathrm{H}_{3} \mathrm{PO}_{4}\right)$ was deposited and analyzed by MALDI-TOF MS. Thin-layer method was used for MALDI-TOFMS analysis. A 4800 plus 
MALDI TOF MS (AB Sciex, Framingham, MA, USA) equipped with a Nd:YAG laser emitting at $355 \mathrm{~nm}$, a repetition rate of $200 \mathrm{~Hz}$ and an acceleration voltage of $20 \mathrm{kV}$ was set to perform data acquisition in positive ion mode. Mass spectra were acquired in the positive ion reflection mode within a scan range of $1000-3500 \mathrm{~m} / \mathrm{z}$.

\section{Results and discussion}

\subsection{Characterization of Ti-CTS}

We synthesized Ti-CTS composite by cross-linking $\mathrm{Ti}^{4+}$ and chitosan. SEM was used to characterize the morphology of the prepared Ti-CTS. As seen from SEM in Fig.1, the as-made materials had uniform shape and considerable rough surface. The BET surface area of Ti-CTS was $9.278 \mathrm{~m}^{2} / \mathrm{g}$. XPS measurement was carried out to confirm the presence of elements in the composite before and after phosphopeptide enrichment (Fig. 2). The XPS spectrum of the Ti-CTS composite before enrichment (Fig. 2a) showed the presence of $\mathrm{C}, \mathrm{N}, \mathrm{O}, \mathrm{Cl}$ and $\mathrm{Ti}$ in the composite. This firstly confirmed the incorporation of $\mathrm{Ti}^{4+}$ ions into chitosan matrix. What's more, after enrichment (Fig. 2b), the addition of $\mathrm{P}$ content and decrease of $\mathrm{Cl}$ element suggested the chelation of phosphate group onto Ti-CTS and the exchange between $\mathrm{Cl}$ and phosphopeptides. The extra F1s peak may come from TFA used in the loading buffer. The results indicated that Ti-CTS composite had high enrichment capacity for phosphopeptide. Hence, possible structure of Ti-CTS was shown in Fig.1b. $\mathrm{Ti}^{4+}$ was chelated between chitosan molecules to form a classical IMAC structure.

Fig. 1

Fig. 2 


\subsection{Enrichment of phosphopeptides by Ti-CTS}

The enrichment of phosphopeptides by Ti-CTS was used by a common capture-washing-elution procedure. Briefly, Ti-CTS composites were incubated with the tryptic digest of proteins for 30 min, and then the supernatant was removed by centrifuging. The phosphopeptides captured on Ti-CTS were washed, eluted and detected using MALDI-TOF MS.

The feasibility of Ti-CTS for specific phosphopeptides capture was investigated using standard phosphopeptides ( $\beta$-casein tryptic digest). Fig.3a demonstrated the MALDI-MS spectrum of the raw digest of $\beta$-casein without enrichment. It was noticed that many peaks were observed in the spectrum, which were dominated by non-phosphoreylated peptides. After enrichment by Ti-CTS (Fig.3b), the peaks of nonphosphorylated peptides were almost disappeared and four phosphopeptides oriented from $\beta$-casein were found and identified, including $2061.9 \mathrm{~m} / \mathrm{z}$ (FQS*EEQQQTEDELQDK), $\quad 2352.6 \mathrm{~m} / \mathrm{z} \quad$ (NVPGEIVESLS*S*S*EES*ITR), $2965.1 \mathrm{~m} / \mathrm{z}$ (RELEELNVPGEIVES*LS*S*S*EESITR), $\quad 3122.3 \quad \mathrm{~m} / \mathrm{z}$ (RELEELNVPGEIVES*LS*S*S*EESITRI). The dephosphorylated fragments of phosphopeptides through loss of $\mathrm{H}_{3} \mathrm{PO}_{4}$ were also observed in the spectrum which indicated that peptide is phosphorylated on serine. The tadam mass spectrometry of one multi-phosphorylated peptide $([\mathrm{M}+\mathrm{H}]=2352.6)$ was carried out as an example to evaluate its multi-phosphorylated sites (Fig. S1). A more interesting thing observed was that three of four phosphopeptides detected using Ti-CTS from $\beta$-casein were multi-phosphorylated peptides with three serine phospholated sites $(S * S * S *)$

Fig. 3

3.3 Selectivity and sensitivity of Ti-CTS for phosphopeptide enrichment 
The selectivity of Ti-CTS composite toward phosphopeptides was evaluated using complex peptides mixture with non-phosphoprotein background. Using BSA protein as a non-phosphoprotein background, tryptic digests of $\alpha$-, $\beta$-casein, and BSA were mixed in different ratios to investigate the selectivity of Ti-CTS. When the molar ratio of BSA to $\alpha-, \beta$-casein was 1:1:10, no obvious phosphopeptides was observed before enrichment (Fig. S2). After enrichment, few non-phosphopeptide was observed and 15 phosphopeptides were recorded (Fig. 4). The major phosphopeptides can be detected with the molar ratio of BSA to $\alpha$-, $\beta$-casein up to 1000:1:1. Similarly most multi-phosphorylated peptides with three serine phospholated sites $(S * S * S *)$ in $\alpha$-casein were captured using Ti-CTS, which were at $\mathrm{m} / \mathrm{z}$ 2703.8(Q*MEAES*IS*S*S*EEIVPNS*VEAQK),

2720.4(QMEAES*IS*S*S*EEIVPNS*VEAQK),

3008.2(NANEEEYSIGS*S*S*EES*AEVATEEVK), 3087.9(NANEEEYS*IGS*S*S*EES*AEVATEEVK).

The high sensitivity of Ti-CTS composite towards phosphopeptides was evaluated by testing $\beta$-casein digests with different concentrations (Fig.5). When the total amount of $\beta$-casein was only $20 \mathrm{fmol}$, two targeted phosphopeptides could be apparently detected (Fig.5d). The signal of one phosphopeptide $(\mathrm{m} / \mathrm{z}=3122)$ could also be well-detected with signal to noise over 3 when the total amount of $\beta$-casein was $10 \mathrm{fmol}$.

Fig. 4

Fig. 5

Considering different aspects of Ti (IV)-chitosan IMAC in the enrichment, a comparison of Ti (IV)-chitosan IMAC with some of reported polymeric materials in phosphopeptides enrichment 
is given in Supporting Information (Table S1). The detection limit, selectivity and enrichment time of the current study are superior or equal than some of them. However the capacity of multi-phosphorylated peptides detection shows superior to most of Ti (IV)-IMAC. It demonstrates that this method is a competitive supplement to Ti (IV)-IMAC materials in phosphopeptides enrichment.

\subsection{Real sample analysis}

In order to further investigate the application ability of Ti-CTS, the more complicated real samples, such as non-fat milk and human serum were tested under our optimal preconcentration conditions. Commercially available non-fat milk constituents of $\alpha$ - and $\beta$-caseins have abundant phosphorylated sites. A number of salts and minerals in milk usually affect the enrichment efficiency. So, direct analysis of non-fat milk is difficult. $4.0 \times 10^{-6} \mathrm{M}$ tryptic digest of non-fat milk was tested using this method. No prominent peak in the spectrum was observed in direct analysis (Fig. S3). After enrichment by Ti-CTS, a number of phosphorylated peptides appear in the spectrum and few non-phosphopeptides were presented (Fig.6a). The detailed information of observed phosphopeptides from non-fat milk were listed in Table 1.

The high background level of highly abundant proteins and complexity of serum samples make phosphopeptide profiling a great challenge. High sensitive and selective phosphopeptide enrichment of the serum level of phosphorylated fibrinogen $\alpha$-chain is in great demand. Ti-CTS is applied to the digested serum under our optimal conditions, one phosphopeptide and many non-phosphopeptides are detected prior to the enrichment (Fig. S4). Four characteristic phosphopeptides from fibrinogen $\alpha$-chain (m/z: 1389.5, 1460.6, 1545.2, 1616.6) are identified after the enrichment (Fig.6b). 
Table 1

Fig.6

\section{Conclusion}

In conclusion, a facile and easy access material based on Ti(IV)-chitosan (Ti-CTS) composite was proposed for specific and effective enrichment toward phosphopeptides. Specifically, Ti-CTS seems to have high affinity to multi-phosphorylated peptides with three serine phospholated sites $(S * S * S *) .9$ multi-phosphorylated peptides including $S * S * S *$ over 15 phosphopeptides were recorded in $\alpha$-, $\beta$-casein and BSA mixture. Also, selective enrichment of phosphopeptides from non-fat milk and human serum were achieved. This work was anticipated to have potential performance in phosphoproteome research.

\section{Acknowledgements}

This work was supported by the National Science Foundation of China (21205041, 21407050), the Fundamental Research Funds for the Central Universities (WK1314039), General Administration of Quality Supervision, Inspection and Quarantine of the People's Republic of China (2014IK077), and a grant of Laboratory team construction program for universities in Shanghai.

\section{References}

[1] C. Crosio, G.M. Fimia, R. Loury, M. Kimura, Y. Okano, H.Y. Zhou, S. Sen, C.D. Allis, P. Sassone-Corsi, Mitotic phosphorylation of histone H3: Spatio-temporal regulation by mammalian aurora kinases, Mol. Cell. Biol., 22 (2002) 874-885.

[2] C. Liu, Y. Li, M. Semenov, C. Han, G.-H. Baeg, Y. Tan, Z. Zhang, X. Lin, X. He, Control of 
$\beta$-Catenin Phosphorylation/Degradation by a Dual-Kinase Mechanism, Cell, 108 (2002) 837-847.

[3] J.E. Sepulveda-Diaz, S.M.A. Naini, M.B. Huynh, M.O. Ouidja, C. Yanicostas, S. Chantepie, J. Villares, F. Lamari, E. Jospin, T.H. van Kuppevelt, A.G. Mensah-Nyagan, R. Raisman-Vozari, N. Soussi-Yanicostas, D. Papy-Garcia, HS3ST2 expression is critical for the abnormal phosphorylation of tau in Alzheimer's disease-related tau pathology, Brain, 138 (2015) 1339-1354. [4] S. Leclerc, M. Garnier, R. Hoessel, D. Marko, J.A. Bibb, G.L. Snyder, P. Greengard, J. Biernat, Y.Z. Wu, E.M. Mandelkow, G. Eisenbrand, L. Meijer, Indirubins inhibit glycogen synthase kinase-3 beta and CDK5/P25, two protein kinases involved in abnormal tau phosphorylation in Alzheimer's disease - A property common to most cycline-dependent kinase inhibitors?, J. Biol. Chem., 276 (2001) 251-260.

[5] P. Cohen, The role of protein phosphorylation in human health and disease - Delivered on June 30th 2001 at the FEBS Meeting in Lisbon, Eur. J. Biochem., 268 (2001) 5001-5010.

[6] A. Stensballe, S. Andersen, O.N. Jensen, Characterization of phosphoproteins from electrophoretic gels by nanoscale $\mathrm{Fe}(\mathrm{III})$ affinity chromatography with off-line mass spectrometry analysis, Proteomics, 1 (2001) 207-222.

[7] J. Martinez-Heredia, J.M. Estanyol, J.L. Ballesca, R. Oliva, Proteomic identification of human sperm proteins, Proteomics, 6 (2006) 4356-4369.

[8] Y. Yan, X. Zhang, C. Deng, Designed Synthesis of Titania Nanoparticles Coated Hierarchially Ordered Macro/Mesoporous Silica for Selective Enrichment of Phosphopeptides, ACS Appl. Mat. Interfaces, 6 (2014) 5467-5471.

[9] L. Beltran, P. Cutillas, Advances in phosphopeptide enrichment techniques for phosphoproteomics, Amino Acids, 43 (2012) 1009-1024. 
[10] J.D. Dunn, E.A. Igrisan, A.M. Palumbo, G.E. Reid, M.L. Bruening, Phosphopeptide enrichment using MALDI plates modified with high-capacity polymer brushes, Anal. Chem., 80 (2008) 5727-5735.

[11] L.A.L. Tang, J.Z. Wang, T.K. Lim, X.Z. Bi, W.C. Lee, Q.S. Lin, Y.T. Chang, C.T. Lim, K.P. Loh, High-Performance Graphene-Titania Platform for Detection of Phosphopeptides in Cancer Cells, Anal. Chem., 84 (2012) 6693-6700.

[12] Y. Yan, Z. Zheng, C. Deng, Y. Li, X. Zhang, P. Yang, Hydrophilic Polydopamine-Coated Graphene for Metal Ion Immobilization as a Novel Immobilized Metal Ion Affinity Chromatography Platform for Phosphoproteome Analysis, Anal. Chem., 85 (2013) 8483-8487.

[13] J. Lu, M.Y. Wang, Y. Li, C.H. Deng, Facile synthesis of TiO2/graphene composites for selective enrichment of phosphopeptides, Nanoscale, 4 (2012) 1577-1580.

[14] M. Dong, M. Ye, K. Cheng, J. Dong, J. Zhu, H. Qin, Y. Bian, H. Zou, Identification of phosphopeptides with unknown cleavage specificity by a de novo sequencing assisted database search strategy, PROTEOMICS, 14 (2014) 2410-2416.

[15] Y. Liang, X. He, L. Chen, Y. Zhang, Facile preparation of graphene/Fe3O4/TiO2 multifunctional composite for highly selective and sensitive enrichment of phosphopeptides, RSC Advances, 4 (2014) 18132-18135.

[16] C. Shi, C. Deng, S. Zou, X. Zhang, Polydopamine-coated eppendorf tubes for Ti4+ immobilization for selective enrichment of phosphopeptides, Talanta, 127 (2014) 88-93.

[17] A. Saeed, M. Najam-ul-Haq, F. Jabeen, F. Svec, High Affinity Phosphopeptides Enrichment and Desalting of Biological Materials on Newly Engineered Poly(Glycidyl Propargyl Ether/Divinyl Benzene), Anal. Chem., 85 (2013) 8979-8986. 
[18] H. Zhou, M. Ye, J. Dong, E. Corradini, A. Cristobal, A.J.R. Heck, H. Zou, S. Mohammed, Robust phosphoproteome enrichment using monodisperse microsphere-based immobilized titanium (IV) ion affinity chromatography, Nat. Protocols, 8 (2013) 461-480.

[19] S. Feng, M.L. Ye, H.J. Zhou, X.G. Jiang, X.N. Jiang, H.F. Zou, B.L. Gong, Immobilized zirconium ion affinity chromatography for specific enrichment of phosphopeptides in phosphoproteome analysis, Molecular \& Cellular Proteomics, 6 (2007) 1656-1665.

[20] Q.Z. Luo, H.F. Zou, X.Z. Xiao, Z. Guo, L. Kong, X.Q. Mao, Chromatographic separation of proteins on metal immobilized iminodiacetic acid-bound molded monolithic rods of macroporous poly(glycidyl methacrylate-co-ethylene dimethacrylate), J. Chromatogr. A, 926 (2001) 255-264.

[21] V.M. Boddu, K. Abburi, J.L. Talbott, E.D. Smith, Removal of hexavalent chromium from wastewater using a new composite chitosan biosorbent, Environmental Science \& Technology, 37 (2003) 4449-4456.

[22] L.F Zhang, W. Xia, B. Teng, X. Liu, W.Q. Zhang, Zirconium cross-linked chitosan composite: Preparation, characterization and application in adsorption of $\mathrm{Cr}(\mathrm{VI})$, Chem. Eng. J., 229 (2013) $1-8$.

[23] L.F. Zhang, W. Xia, X. Liu, W.Q. Zhang, Synthesis of titanium cross-linked chitosan composite for efficient adsorption and detoxification of hexavalent chromium from water, J. Mater. Chem. A, 3 (2015) 331-340.

[24] V.M. Boddu, K. Abburi, J.L. Talbott, E.D. Smith, R. Haasch, Removal of arsenic(III) and arsenic(V) from aqueous medium using chitosan-coated biosorbent, Water Res., 42 (2008) 633-642.

[25] S.R. Popuri, Y. Vijaya, V.M. Boddu, K. Abburi, Adsorptive removal of copper and nickel ions 
from water using chitosan coated PVC beads, Bioresour. Technol., 100 (2009) 194-199.

[26] J. Sun, Y.T. Liu, Y.J. Su, W.S. Xia, Y.J. Yang, Highly efficient enrichment of phosvitin phosphopeptides by novel magnetic carboxymethyl chitosan nanoparticles decorated with $\mathrm{Fe}$ (III) ions, J Chromatogr. B, 915-916 (2013) 33-38.

\section{Figure captions:}

Fig1. (A) SEM image of Ti-CTS; (B) Possible structure of Ti-CTS.

Fig.2 XPS spectra and elemental composites (a) before and (b) after phosphopeptide enrichment.

Fig.3.(a) MALDI mass spectrum of the tryptic digest of 10 pmol $\beta$-casein without enrichment and (b) MALDI mass spectrum of the samples after using Ti-CTS to selectively trap target phosphopeptides from the tryptic digest of $\beta$-casein. Where \# indicates the metastablelosses of phosphoric acid.

Fig. 4 MALDI-MS spectrum after enrichment using Ti-CTS for mixture of $\alpha-/ \beta$-casein/ BSA digest (1:1:10). Where \# indicates the metastablelosses of phosphoric acid.

Fig. 5 MALDI-MS spectra obtained after enrichment the tryptic digest of $\beta$-casein with different concentrations by Ti-CTS composite. (a) 20 pmol; (b) 2 pmol; (c) 200 fmol; (d) 20 fmol. The numbers marked on peaks corresponded to that in Table 1.

Fig.6. (a)MALDI mass spectrum of peptides derived from non-fat milk enrichment employing 
Ti-CTS, and (b) MALDI mass spectrum of peptides derived from human serum employing Ti-CTS. The \# indicates the metastable losses of phosphoric acid. The * indicates the metastable losses of metaphosphoric acid. (The m/z of F1,F2, F3, F4 are 1389.5, 1460.6, 1545.2 and 1616.6.) 
Table 1 Phosphorylation Sites and the Sequence of Identified Peptides in Non-fat Milk Enriched by Ti-CTS

\begin{tabular}{llll}
\hline Proteins & Peptide sequence & No. of & {$[\mathrm{M}+\mathrm{H}]+$} \\
& & phosphate \\
& & groups \\
& & 1 & 1197.0 \\
$\alpha 1$ & KNMAINPS*KENL & 1 & 1466.6 \\
$\alpha 2$ & TVDMES*TEVFTK & 1 & 1660.5 \\
$\alpha 3$ & VPQLEIVPNS*AEER & 2 & 1927.6 \\
$\alpha 4$ & DIGS*ES*TEDQAMEDIK & 1 & 1951.9 \\
$\alpha 5$ & YKVPQLEIVPNS*AEERL & 5 & 2593.9 \\
$\alpha 6$ & QMEAES*IS*S*S*EEIVPNS*VEQ & 4 & 2624.0 \\
$\alpha 7$ & pyroQMEAES*IS*S*S*EEIVPNSVEQK & 4 & 2703.8 \\
$\alpha 8$ & pyroQMEAES*IS*S*S*EEIVPNS*VEAQK & 5 & 2720.4 \\
$\alpha 9$ & QMEAES*IS*S*S*EEIVPNS*VEAQK & 5 & 3008.2 \\
$\alpha 10$ & NANEEEYSIGS*S*S*EES*AEVATEEVK & 4 & 3087.9 \\
$\alpha 11$ & NANEEEYS*IGS*S*S*EES*AEVATEEVK & 5 & 2061.8 \\
$\beta 1$ & FQS*EEQQQTEDELQ & 1 & 2352.6 \\
$\beta 2$ & NVPGEIVESLS*S*S*EES*ITR & 4 & 2965.1 \\
\hline 34 & RELEELNVPGEIVES*LS*S*S*EESITR & 4 & 312.3 \\
\hline
\end{tabular}

The $\alpha, \beta$ in the peptide number refers to the fact that the peptide is phosphorylated. pyroQ: Pyroglutamylation on the N-terminal Gln, $S^{*}$ : phosphorylated residue. 
Fig. 1
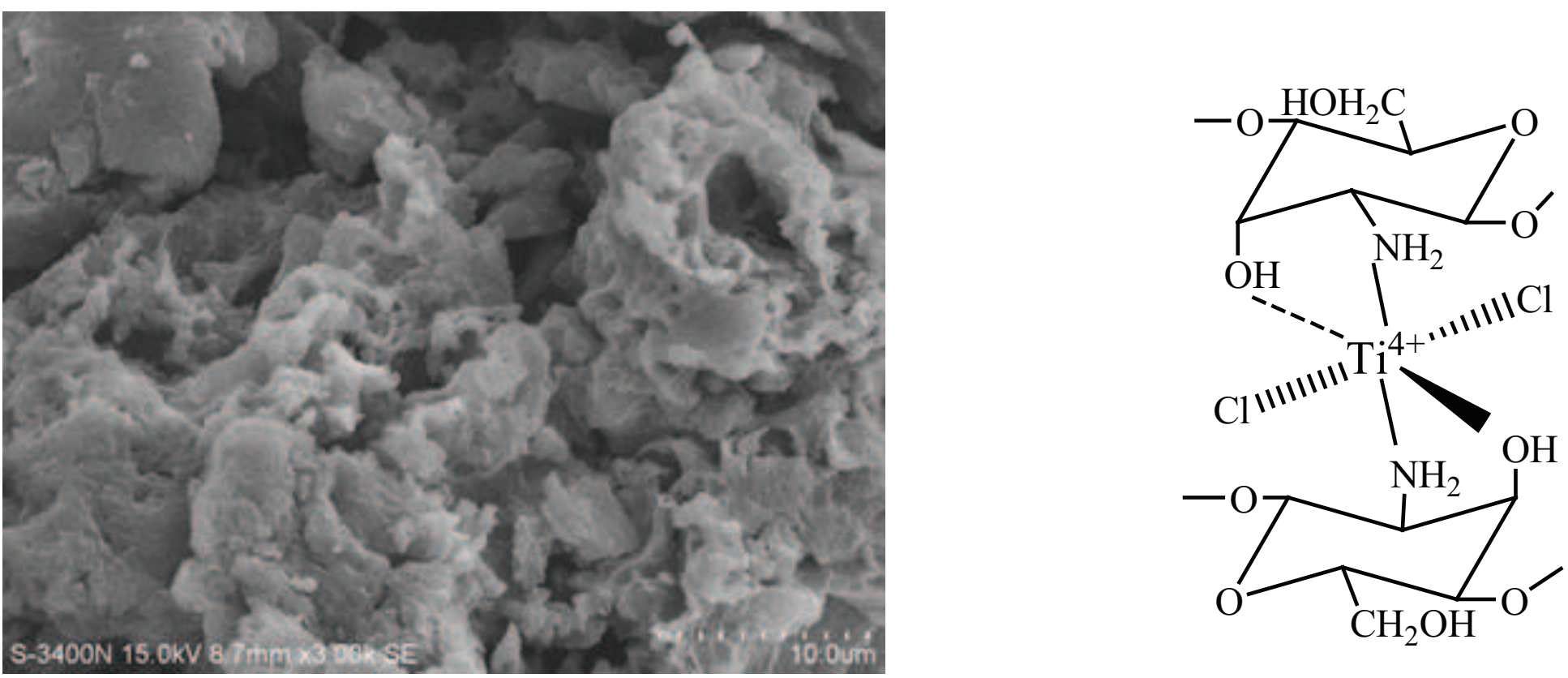
Fig.2
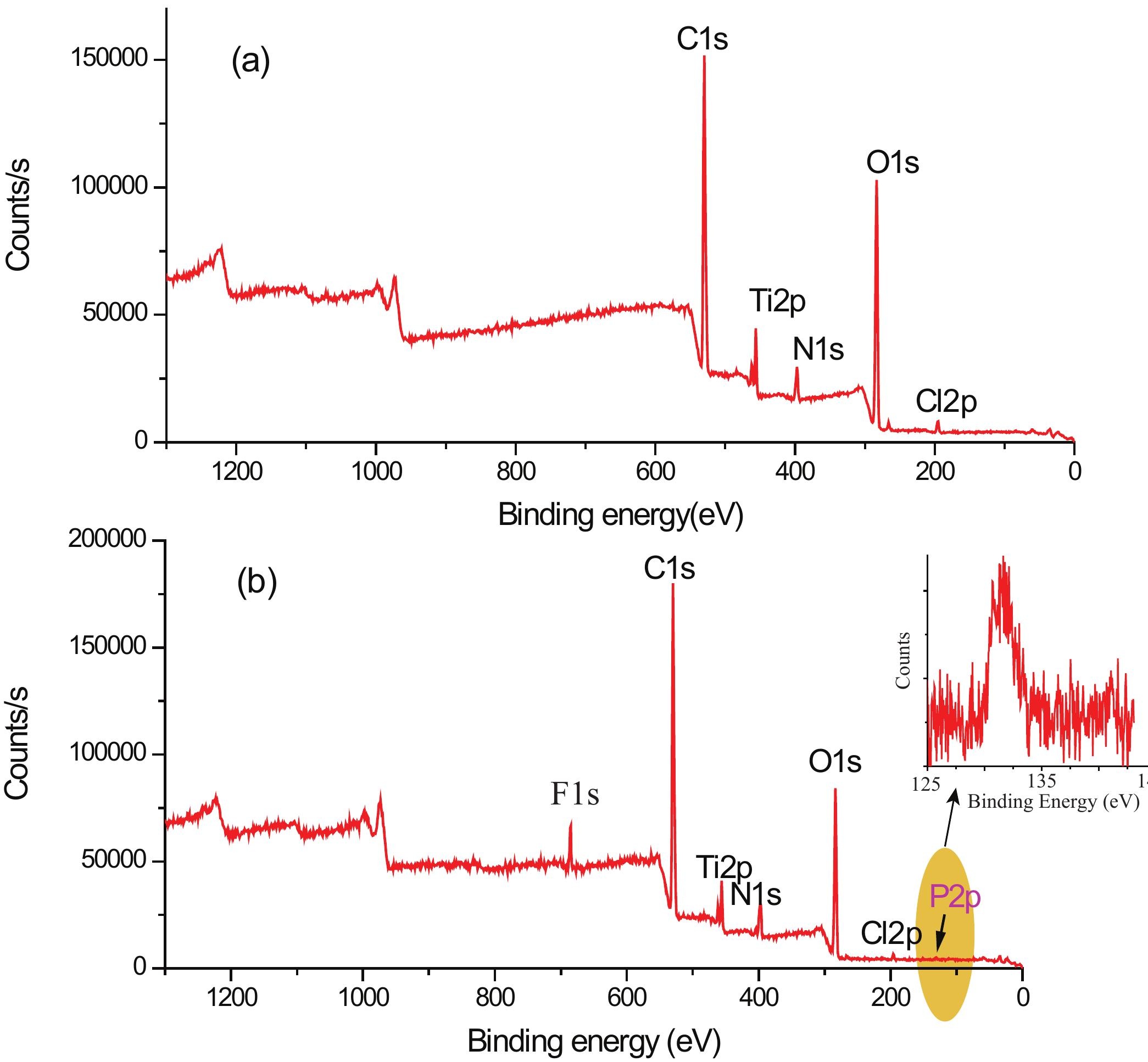
Fig.3

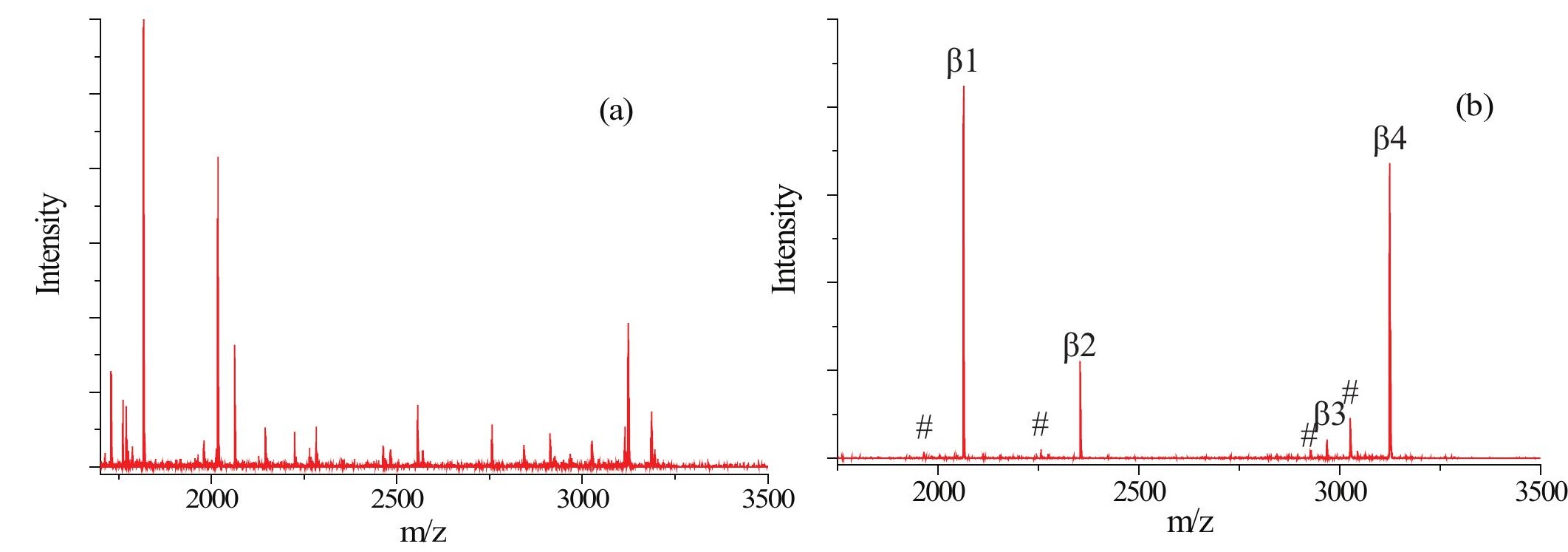


Fig. 4

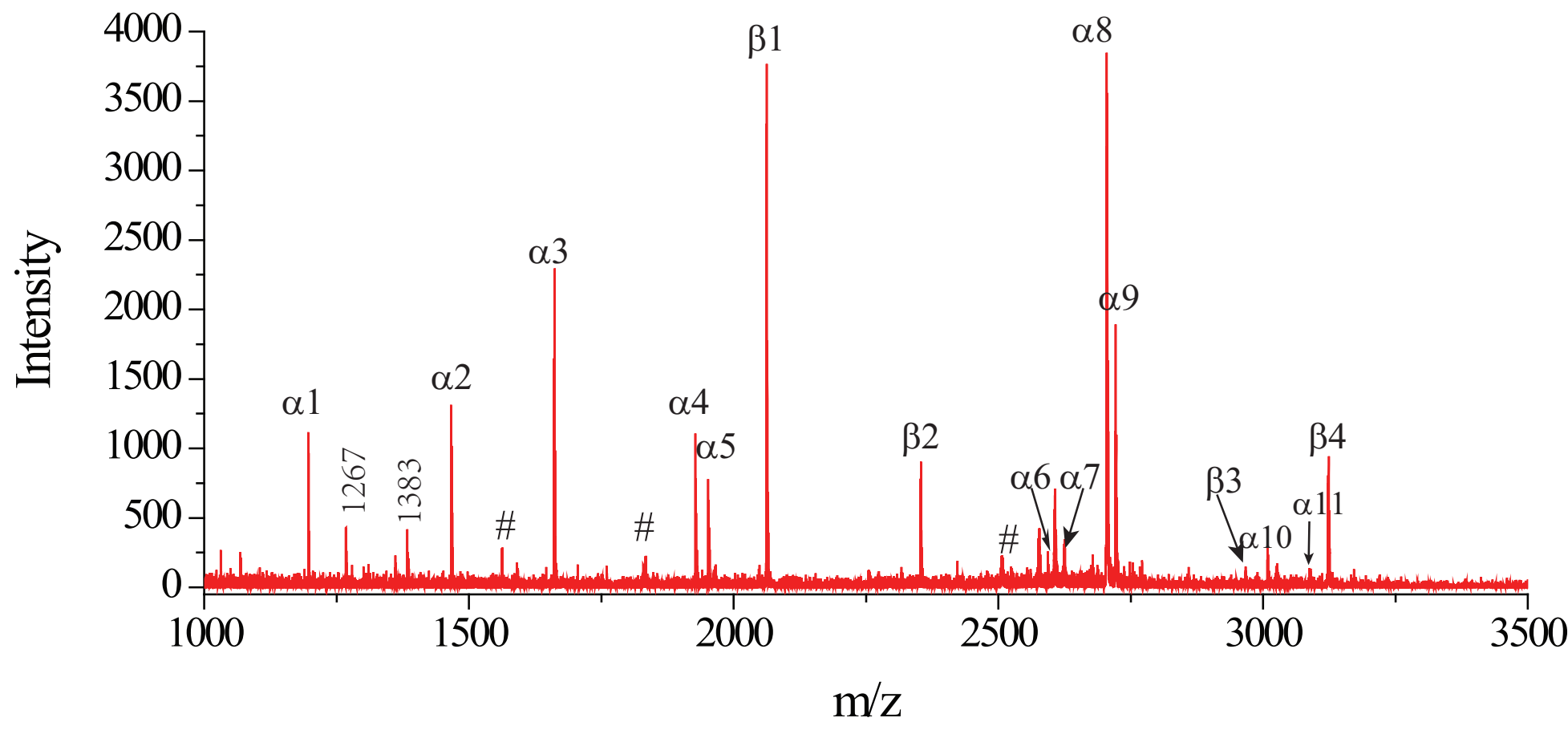


Fig.5
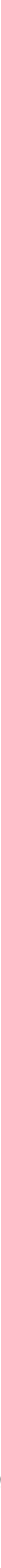
Fig. 6

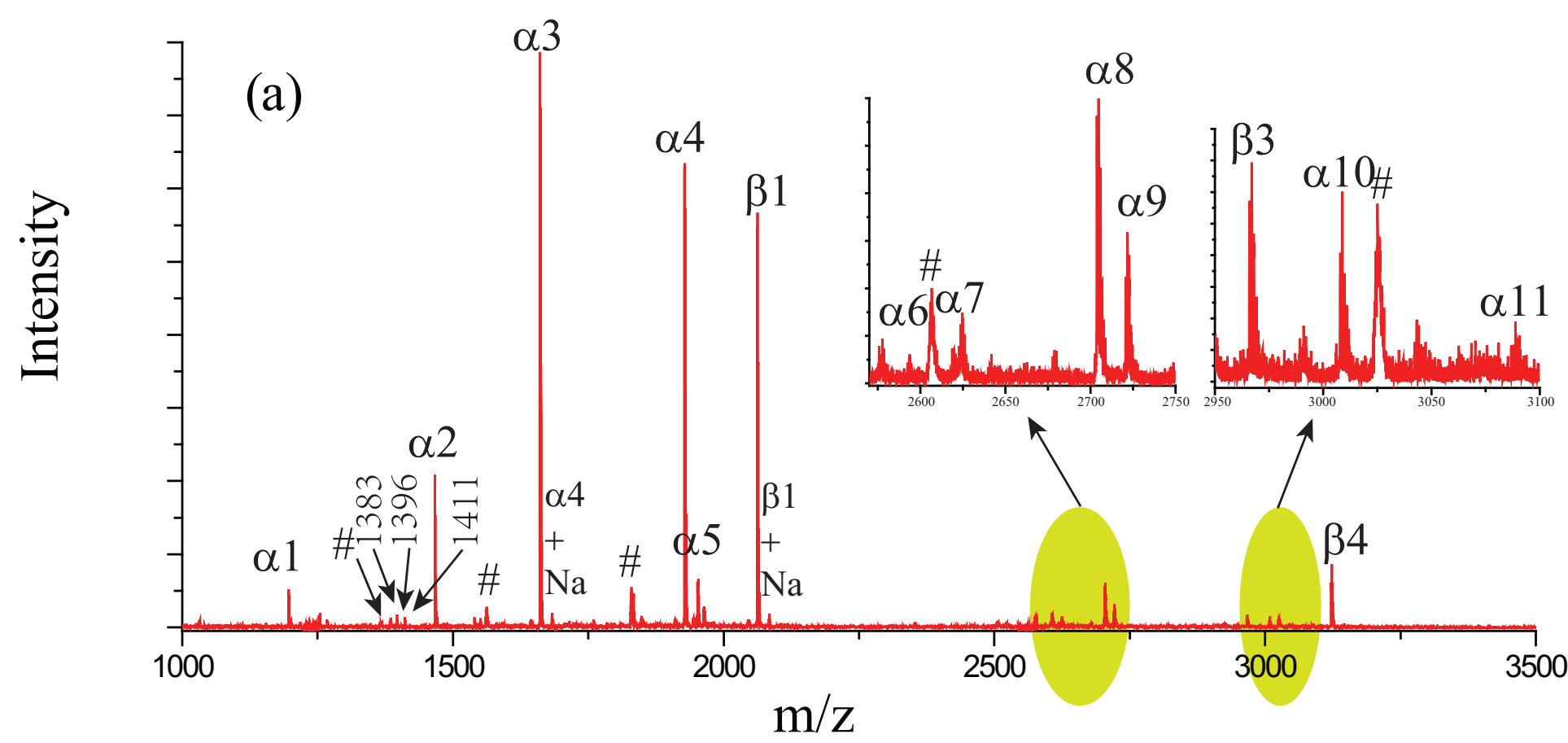

F4

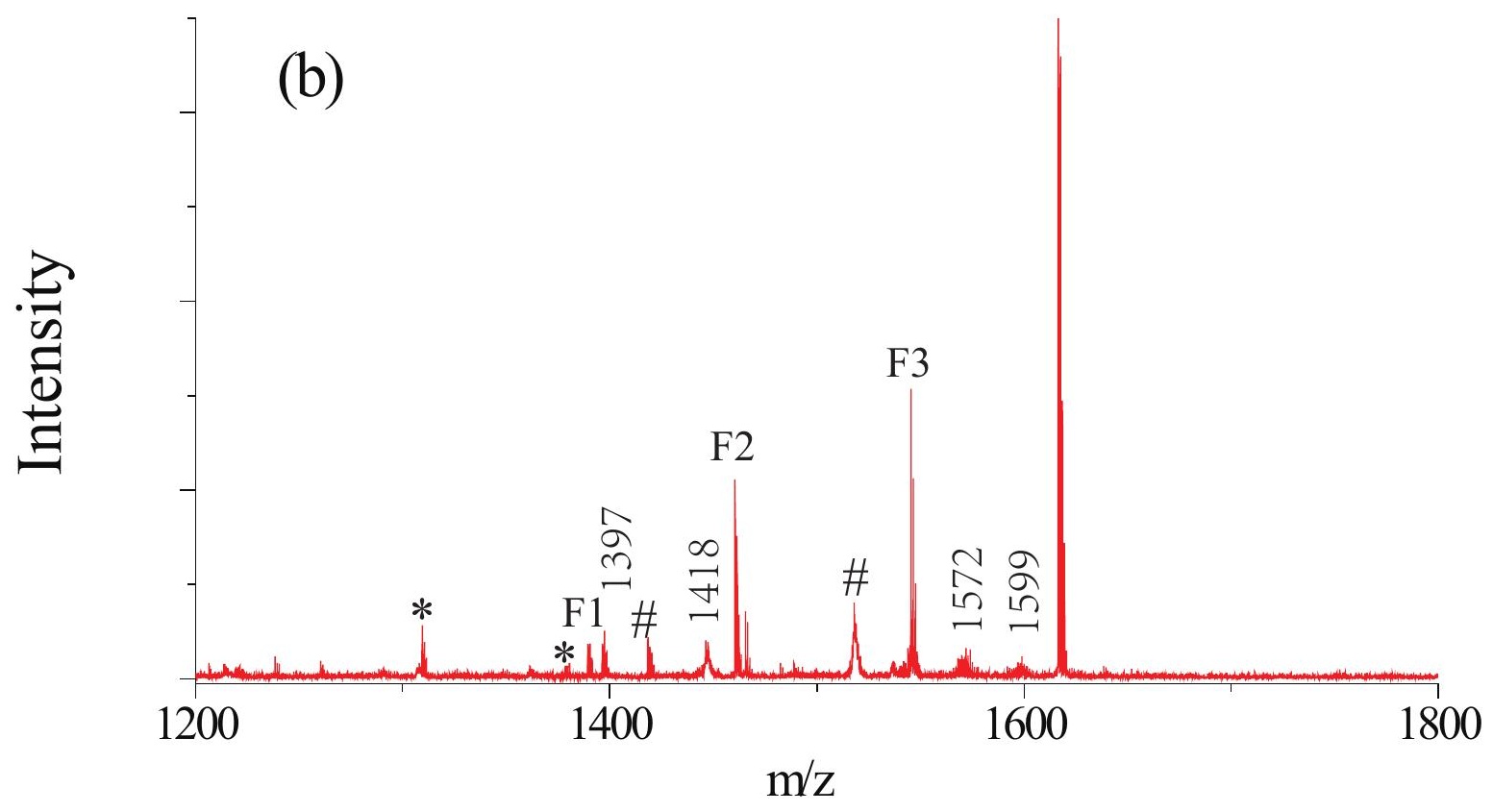

